\title{
What Do Children and Chimpanzees Reveal About Human Altruism?
}

\section{Citation}

Warneken, Felix. 2013. What Do Children and Chimpanzees Reveal About Human Altruism? In "What Infants, Children, and Other Species Can Teach Us", ed. Mahzarin R. Banaji, Susan A, Gelman. 395-400. Oxford: Oxford University Press.

\section{Published Version}

doi:10.1093/acprof:oso/9780199890712.003.0073

\section{Permanent link}

http://nrs.harvard.edu/urn-3:HUL.InstRepos:34796158

\section{Terms of Use}

This article was downloaded from Harvard University's DASH repository, and is made available under the terms and conditions applicable to Open Access Policy Articles, as set forth at http:// nrs.harvard.edu/urn-3:HUL.InstRepos:dash.current.terms-of-use\#OAP

\section{Share Your Story}

The Harvard community has made this article openly available.

Please share how this access benefits you. Submit a story.

Accessibility 


\title{
What Do Children and Chimpanzees Reveal about Human Altruism?
}

\author{
Felix Warneken \\ Harvard University \\ warneken@wjh.harvard.edu
}

Philosophers, psychologists, and biologists have long debated the basis of human altruistic behavior. Proponents of a more Hobbesian worldview argue that altruistic behaviors mainly depend upon the acquisition of social norms which override and control our pervasive selfish nature. On the other hand, followers of Rousseau support the idea that we might have basic altruistic tendencies to care about others, which do not depend on social norms alone. While it is unlikely that there is an easy solution to this perennial debate, recent advances in the behavioral sciences allow us to formulate these questions more clearly and provide the empirical evidence to address them. In this chapter, I argue that a critical task for this endeavor is to investigate the proximate or psychological mechanisms underlying these behaviors, and trace their emergence in human ontogeny and phylogeny ${ }^{1}$. That is, focusing solely on the mature state of altruistic behaviors in human adults cannot provide us with a satisfactory answers. Secondly, I will summarize some of the most recent empirical findings that this approach has produced, examining both early child

\footnotetext{
${ }^{1}$ I will focus on psychological (i.e. proximate) mechanisms, not ultimate function. 'Altruistic' is thus used in terms of the underlying motivation, i.e. a behavior that is aimed at produce a concrete benefit to another individual rather than oneself. This does not necessarily imply altruism in terms of fitness costs and benefits as a different level of analysis. For details see e.g. Warneken \& Tomasello (2009a) and de Waal (2008).
} 
development and comparisons with one of our closest evolutionary relatives chimpanzees. Studies on children's helping behaviors show that humans act altruistically from a very early age, before specific socialization factors such as the teaching of cultural norms could have had a major impact on their development. Moreover, even chimpanzees on occasion act helpfully towards others - raising the possibility that humans are perhaps not as special in their psychology as one might think. These findings provide new insights-but also raise new questions-for the debate about human nature dating back to Hobbes and Rousseau.

\section{Helping in human children}

Why study children? Research on adults has established that factors such as the adherence to social norms and reputation formation play a major role in social life, especially when altruistic behaviors are concerned. On the other end, children are often characterized as acting based upon selfish motivations alone, not considering the welfare of others before they have acquired specific prosocial norms. Therefore, it has been proposed that socialization practices such as the internalization of social norms and rewarding appropriate behaviors are the major (and perhaps only) factor accounting for the emergence of altruistic behaviors in development (e.g. Bar-

Tal, 1982; Dovidio, Piliavin, Schroeder, \& Penner, 2006; Henrich, et al., 2005). However, these claims are mainly based upon studies of school-aged children or adults who have already gone through a long socialization period. Therefore, studying young children is essential to determine whether these proposed 
socialization practices are actually the starting point of altruistic behaviors or, alternatively, build upon an early emerging and perhaps biological predisposition.

One of the earliest manifestations of altruistic inclinations can be found in simple helping behaviors in which one person struggles to complete a task and the child can intervene. For most of the chapter, I will focus on these 'instrumental helping' behaviors because they are particularly interesting for the topic of this book: social cognition. Specifically, in order to competently help someone with an instrumental problem, the child has to have the social-cognitive capacity to represent the other person's unfulfilled goal, as well as the motivation to act on that goal. Thus, these cases of instrumental helping differ from other altruistic behaviors such as sharing (where the problem consists in a lack of resource and the intervention is to give up part of one's own) and empathic intervention (where the actor comforts a person in distress, responding to emotional needs) (Dunfield, Kuhlmeier, O'Connell, \& Kelley, 2010; Svetlova et al., 2010; Warneken \& Tomasello, 2009a,b). Thus, in instrumental helping situations, actors can utilize their ability to represent other people's goals to intervene on behalf of others.

Young children start to help surprisingly early, not long after their first birthday. In an initial study, we presented 18-month-old infants with ten different situations in which an adult was having trouble achieving a goal (Warneken \& Tomasello, 2006; see also Rheingold, 1982). For instance, an experimenter may be accidentally dropping clothespins while hanging towels on a line or banging helplessly into a cabinet door with a stack of magazines in his hands. In these kinds 
of situations, children displayed spontaneous, unrewarded helping behaviors across in a variety of ways. They handed over dropped objects, completed an action after his failed attempt at stacking books, opened the door of a cabinet for him, and brought about the experimenter's goal by different means: rather than using the experimenter's wrong approach to try to squeeze his hand through a tiny hole in order to retrieve an object from a box, children lifted a flap on the side of the box and gave the object to him. Even 14-month-old children act helpfully, although at this early age only with cognitively less demanding tasks (such as a person reaching for an object) (Warneken \& Tomasello, 2007). Further evidence for an ontogenetic shift comes from a study by Svetlova and colleagues, in which children from 18 to 24 months were more likely to help with concrete goals (such as reaching for a dropped object) than with tasks which involved at least one more inferential step (such as bringing a blanket to a person who is shivering) (Svetlova, Nichols, \& Brownell, 2010). Thus, one factor contributing to the emergence of children's helping behaviors seems to be their developing social cognitive capacity to infer other's goals and choose the appropriate type of intervention.

Even more impressively, during the second year of life toddlers begin to infer the other person's goal based upon his state of knowledge or ignorance (Buttelmann, Carpenter \& Tomasello, 2009). In this experiment a toy was moved from one opaque box A to another opaque box B either in the protagonist's absence (ignorant condition) or presence (knowledge condition). When the protagonist subsequently failed to open box A, children from the ignorant condition opened box B (perhaps thinking that he falsely tries to open box A because he is ignorant of the 
toy's true location), whereas children form the knowledge condition were more likely to open box A (perhaps thinking that he must have a new goal in mind). Thus, this indicates that young children actually help other people with their goals (and not just complete a concrete action such as the failure to open something), and are able to infer goals from representations about the other person's state of knowledge versus ignorance. Taken together, these studies show that shortly after their first birthdays, human children begin to spontaneously help others, becoming more flexible in their ability to intervene in various types of situations over the second year of life.

Children are thus able to help - but what exactly motivates their helping? Perhaps importantly, helping occurs spontaneously in the parent's absence, proving that it is not due to subtle cues from the parent, obedience to parental authority or the expectation of praise (Warneken \& Tomasello, submitted). Moreover, these toddlers are willing to put some effort into helping, as they literally toddle over obstacles over and over again to help another person or help over and over again despite having to leave a fun game behind (Warneken et al., 2007; Warneken \& Tomasello, 2008, Warneken \& Tomasello, submitted). Last but not least, concrete rewards do not seem to drive children's helping. Specifically, in a study of 18month-olds, children who were offered a toy as a reward for helping were not more likely to help over ten consecutive trials than children who helped without being given a reward (Warneken et al., 2007). As a matter of fact, concrete rewards can even have a negative effect on children's helping: During an initial phase of an experiment, different children were either offered a reward for helping, were 
praised, or neither rewarded nor praised (Warneken \& Tomasello, 2008). During the subsequent test phase, neither group of children received praise or rewards in for helping. Interestingly, children who had previously been rewarded were now less likely to continue to help than the children from the other two conditions. This indicates that children have an intrinsic motivation to help in these situations, and external rewards undermine this tendency.

Taken together, these results provide evidence for an early emergence of basic altruistic tendencies. Toddlers utilize their social cognitive capacities to help others in need. Experimental manipulations rule out certain situational factors such as rewards or parental encouragement. Moreover, the fact that these helping behaviors emerge so early in life renders certain hypotheses about socialization practices as the driving factor as rather implausible. For example, we can rule out the claim that children are initially oblivious to the needs of others and help only when promised concrete rewards (e.g. Cialdini, Kenrick, and Baumann, 1982) or that humans develop spontaneous helping behaviors only after a long reward history until ultimately helping becomes self-rewarding around adolescence (e.g. Bar-Tal, 1982). It is similarly implausible to assume that these young children have already adopted a moral value system that guides their behavior. Moreover, there is no indication that these young children are adept at reputation management, an ability that does no seem to emerge before school-age (Aloise-Young, 1993; Banerjee, 2002). It is of course possible that parental reinforcement elicits these behaviors. However, there are several problems with an approach that relies on social reinforcement alone. First, natural observations with children show that 
parents do not appear to systematically reward altruistic behaviors with material rewards, but most of the time just acknowledge the helpful act (Grusec, 1991 with 4year-old children). Second, even if those occurred, infants at 14 to 18 months of age had little opportunity to be reinforced for helping. Third, studies with older children show that the inducement of altruistic behaviors through concrete reinforcements or punishment do not transfer to other types of situations or interactions with other people - when the incentive disappears, so does the behavior (Moore \& Eisenberg, 1984). The reported studies, however, demonstrate that children help also in novel situations with an unfamiliar adult in situations for which they could not have possibly been rewarded in the past. Fourth, as described above, external rewards can have negative effects on helping in an experimental situation. This is corroborated by a longitudinal observational study in which the amount of parental reinforcement of compliant altruistic behavior was negatively correlated with behaviors towards a peer two years later (Eisenberg, Wolchik, Goldberg, \& Engel, 1992). Given these data, it seems rather implausible to assume that young children are initially totally self-focused and oblivious to the needs of other, with socialization practices completely re-programming children's motivations.

Nevertheless, it is still possible that there are certain socialization practices early in life that have not been captured in previous studies. Perhaps children are particularly adept social learners when it comes to helping behaviors, or perhaps adults are particularly motivated to raise altruistic offspring. For example, children may learn to help because they imitate other people's helping behaviors. Unfortunately, no studies with infants and toddlers directly address this topic in 
very young children. However, indirect evidence comes from a very different source: studies of chimpanzees. If socialization practices such as teaching helpful behavior or internalizing social norms are a necessary prerequisite for the emergence of the kinds of altruistic behaviors we see in young children, we would not expect to find them in chimpanzees. Although chimpanzees show flexible socialcognitive skills (e.g. Tomasello et al., 2005; but see Povinelli \& Vonk, 2003, for an opposing view) and may transmit some cultural information about some domains of life such as tool use (e.g. Whiten et al., 2009), there is currently no indication that chimpanzees transmit cultural norms about appropriate social behavior or actively reward their offspring for social behaviors towards others. Thus, studies with chimpanzees can inform us whether these types of socialization factors are actually necessary for helping behaviors to emerge. Not only that, comparative studies of humans and chimpanzees enable us to time-travel into our evolutionary past, differentiating between those aspects that might have characterized the common ancestor of humans and nonhuman apes 5 to 7 million years ago from those behaviors that evolved only in the human lineage.

\section{Helping in chimpanzees}

It is currently a matter of debate to what extent chimpanzees display similar altruistic behaviors. On the one hand, there are recent experiments demonstrating that chimpanzees do not take the opportunity to act on behalf of another individual. In particular, chimpanzees did not reliably deliver food to a conspecific by pulling a board within reach of them-unless this would result in a reward for them actor as 
well (Jensen et al., 2007). When faced with the choice to activate a mechanism that delivers either food to the actor and a recipient (the $1 / 1$ option) or only to the recipient (the 1/0 option), chimpanzees chose at random (Silk et al. 2006; see Silk, this volume, for details). On the other hand, our studies of instrumental helping provides evidence that chimpanzees might in fact have altruistic motivations. These different results raise interesting questions about the proximate mechanisms that are involved in altruistic behavior and highlight important differences and similarities in humans and chimpanzees.

The first piece of experimental evidence suggesting that chimpanzees might be altruistic in some contexts came from an study on instrumental helping in human-reared chimpanzees. When we tested them in the same tasks as the 18month-old toddlers described above, we found that chimpanzees would also help their caregiver when she was reaching for an object (Warneken \& Tomasello, 2006). They did this without being offered a reward and did not pick up the objects in matched control conditions in which there was no indication by the caregiver that she needed help. These chimpanzees were thus able to determine the caregiver's goal and had the motivation to help her achieve it. Moreover, this phenomenon is not restricted to human-raised chimpanzees who interact with their human surrogate mother: a second study with semi-free ranging chimpanzees indicated that they would help a human stranger with whom they had no prior interaction when he was reaching for objects (Warneken et al., 2007). They gave the object more often when he was reaching for it than when he was not reaching for it. And perhaps most surprisingly, as with children, the apes were equally likely to help 
when the human was offering a reward (here, a piece of food) then when they were not offered the reward. This indicates that the chimpanzees were motivated to help the experimenter with his unachieved goal, and not by the possibility of retrieving a material reward for themselves.

One problem with these situations is that the chimpanzees were helping humans, not other chimpanzees. To test whether chimpanzees would also help their conspecifics, we created an experimental situation in which one chimpanzee (the recipient) was faced with the problem: a door leading to a room with a piece of food was fixed with a chain that she could not unlock (Warneken et al., 2007). But if another chimpanzee (the actor) released this chain from an adjacent room, the recipient would be able to enter. Results showed that chimpanzees often released the chain - significantly more often than in different control conditions, in which releasing the chain would either not help the recipient or no recipient was present. This shows that subjects were attentive to the recipient's goal, intervening on the recipient's behalf when she unsuccessfully trying to open the door. Taken together, this line of experiments indicates that chimpanzees also have the cognitive and motivational prerequisites to perform acts of instrumental helping.

These experiments provide an interesting contrast to other experimental paradigms in which chimpanzees did not actively deliver food rewards to conspecifics, raising interesting questions about the types of altruistic behavior that humans and our closest relatives engage in (Warneken \& Tomasello, 2009b). Specifically, we hypothesized that perhaps chimpanzees are so competitive over 
food that they are reluctant to actively provide food to others, even if they are unable to obtain it for themselves. Alternatively, the active problem-solving activity that is inherent in the instrumental helping situation might make the recipient's unfulfilled goal and the need for intervention more salient than the sharing contexts in which the recipients are not engaged in a task and remain mainly passive. To measure the importance of both factors, we manipulated them experimentally within a single experimental paradigm (Melis et al., 2010). Here, the actor could release a bag with a reward, which would slide down a chute to the recipient in another room. To test the food hypothesis, we manipulated whether the bag contained food or a token. To test the activity hypothesis, we also manipulated whether the recipient could actively try to pull at a roped attached to the bag or had no such opportunity. Results showed that chimpanzees were equally likely to help with food rewards or tokens: helping was not diminished when food was involved. Importantly, actors helped more often when the recipient was actively trying to access the reward by pulling the rope or communicated with the actor than when the recipient remained passive (see Yamamoto, Humle, \& Tanaka, 2009, for a similar finding). Thus, an important factor predicting helping in chimpanzees appears to be the activity of the recipient signaling the need for help.

Taken together, these studies show that not unlike human infants, chimpanzees instrumentally help others - at least when the problem is made salient. It is important to note, however, that despite this similarity, altruistic behaviors in chimpanzee appear to be much more restricted than what we see in humans (see Warneken \& Tomasello, 2009b, for details). This is particularly true 
when it comes to food sharing, as chimpanzees rarely share food that they could keep for themselves, and food transfers occurring mainly in instances of 'tolerated theft', in which one individual allows another individual taking food, often after being harassed rather than pro-actively handing over food (Gilby, 2006). One the other hand, in situations with other demands, such as a concrete instrumental problem, chimpanzees appear to be willing to lend a hand. Thus, to compare species, it seems important to assess a variety of behaviors. This will enable us to better understand the proximate factors that enable and constrain altruistic behaviors in humans and our closest relatives.

\section{Conclusion}

Young children engage in helping behaviors and so do chimpanzees. These findings indicate that the basic social cognitive and motivational processes have deep roots in ontogeny and phylogeny. In particular, these results challenge the idea that human altruistic behaviors are due to socialization practices in the form of parental instruction or the internalization of norms alone. There is no question that socialization practices can profoundly influence children's basic altruistic tendencies (to the better or worse). However, it seems like these practices can build upon processes that we share with our closest evolutionary relatives, rather than completely reshaping our biological endowment.

Moreover, recent findings from comparative and developmental psychology indicate that altruistic behavior should not be viewed as a unitary trait. There are different ways that humans can engage in altruistic behavior, and these varieties 
may be supported by distinct psychological mechanisms. Moreover, different varieties of altruism may differ in how they are manifested across species, such as in terms of food provision and instrumental helping in chimpanzees. Thus, investigating the circumstances under which humans and other animals do and do not act on behalf of others will provide further insight into the similarities and differences in a behavior that is a cornerstone of human social life.

\section{Acknowledgments}

Thanks to Alexandra Rosati for helpful comments on an earlier draft.

\section{References}

Aloise-Young, P. A. (1993). The Development of Self-Presentation: Self-Promotion in 6- to 10-Year-Old Children. Social Cognition, 11(2), 201-222.

Banerjee, R. (2002). Children's Understanding of Self-Presentational Behavior: Links With Mental-State Reasoning and the Attribution of Embarrassment. MerrillPalmer Quarterly, 48(4), 378-404.

Bar-Tal, D. (1982). Sequential development of helping behavior: A cognitivelearning approach. Developmental Review, 2, 101-124.

Buttelmann, D., Carpenter, M., \& Tomasello, M. (2009). Eighteen-month-old infants show false belief understanding in an active helping paradigm. Cognition, $112,337-342$.

Cialdini, R. B., Kenrick D. T. , \& Baumann, D. J. (1982). Effects of mood on prosocial 
behavior in children and adults. In N. Eisenberg (Ed.), The development of prosocial behavior (pp. 339-359). San Diego, CA: Academic Press.

de Waal, F.B.M. (2008). Putting the Altruism Back into Altruism: The Evolution of Empathy. Annual Review of Psychology, 59, 279-300.

Dovidio, J. F., Piliavin, J. A., Schroeder, D. A., \& Penner, L. A. (2006). The social psychology of prosocial behavior. Mahwah, New Jersey: Lawrence Erlbaum Associates.

Dunfield, K. A., Kuhlmeier, V. A., O'Connell, L. J., \& Kelley, E. A. (2010). Examining the Diversity of Prosocial Behaviour: Helping, Sharing, and Comforting in Infancy.

Eisenberg, N., Wolchik, S., Goldberg, L., \& Engel, I. (1992). Parental values, reinforcement, and young children's prosocial behavior. Journal of Genetic Psychology, 153, 19-36.

Gilby, I. C. (2006). Meat sharing among the Gombe chimpanzees: harassment and reciprocal exchange. Animal Behavior, 71, 953 - 963.

Grusec, J. (1991). Socializing Concern for Others in the Home. Developmental Psychology, 27(2), 338-342.

Henrich, J., Boyd, R., Bowles, S., Camerer, C. F., Fehr, E., Gintis, H., et al. (2005). "Economic man" in cross-cultural perspective: Behavioral experiments in 15 small-scale societies. Behavioral \& Brain Sciences, 28, 795 - 855.

Jensen, K., Hare, B., Call, J., \& Tomasello, M. (2006). What's in it for me? Self-regard precludes altruism and spite in chimpanzees. Proceedings of the Royal Society $B, 273,1013-1021$. 
Melis, A. P., Warneken, F., Jensen, K., Schneider, A.-C., Call, J., \& Tomasello, M. (2010). Chimpanzees help conspecifics obtain food and non-food items. Proceedings of the Royal Society B. doi:10.1098/rspb.2010.1735

Moore, B., \& Eisenberg, N. (1984). The Development of Altruism. Annals of Child Development, 1, 107-174.

Povinelli, D., and Vonk, J. (2003). Chimpanzee minds: Suspiciously human? Trends in Cognitive Science, 7, 157 - 160.

Rheingold, H. L. (1982). Little children's participation in the work of adults, a nascent prosocial behavior. Child Development, 53(1), 114-125.

Silk, J., Brosnan, S., Vonk, J., Henrich, J., Povinelli, D., Richardson, A. S., et al. (2005). Chimpanzees are indifferent to the welfare of unrelated group members. Nature, 437, 1357-1359.

Svetlova, M., Nichols, S.R., \& Brownell, C.A. (2010) Toddlers' Prosocial Behavior: From Instrumental to Empathic to Altruistic Helping, Child Development, 81 (6) 1814-1827.

Warneken, F., Hare, B., Melis, A. P., Hanus, D., \& Tomasello, M. (2007). Spontaneous altruism by chimpanzees and young children. PLoS Biology, 5 (7), 1414 1420.

Warneken, F., \& Tomasello, M. (2006). Altruistic Helping in Human Infants and Young Chimpanzees. Science, 311, 1301-1303. 
Warneken, F., \& Tomasello, M. (2007). Helping and cooperation at 14 months of age. Infancy, 11(3), 271 - 294.

Warneken, F., \& Tomasello, M. (2008). Extrinsic rewards undermine altruistic tendencies in 20-month-olds. Developmental Psychology, 44(6), 1785-1788.

Warneken, F., \& Tomasello, M. (2009a). The roots of human altruism. British Journal of Psychology, 100, 455-471.

Warneken, F., \& Tomasello, M. (2009b). Varieties of altruism in children and chimpanzees. Trends in Cognitive Sciences, 13,9, 397-482.

Whiten, A., McGuigan, N., Marshall-Pescini, S., Hopper, L.M. (2009) Emulation, imitation, overimitation and the scope of culture for child and chimpanzee. Philosophical Transactions of the Royal Society B, 364, 2417-242.

Yamamoto, S., Humle, T., \& Tanaka, M. (2009). Chimpanzees Help Each Other upon Request. PLoS ONE 4(10): e7416. doi:10.1371/journal.pone.0007416. 